\title{
Phase I dose-escalation trial of intravaginal curcumin in women for cervical dysplasia
}

This article was published in the following Dove Press journal:

Open Access Journal of Clinical Trials

22 December 2016

Number of times this article has been viewed

\section{Leda Gattoc' \\ Paula M Frew ${ }^{2-4}$ \\ Shontell N Thomas ${ }^{5}$ \\ Kirk A Easley ${ }^{6}$ \\ Laura Ward ${ }^{6}$ \\ $\mathrm{H}-\mathrm{H}$ Sherry Chow ${ }^{7}$ \\ Chiemi A Ura ${ }^{8}$ \\ Lisa Flowers ${ }^{8}$}

'Division of Gynecologic Oncology, Wayne State University, Detroit, MI, ${ }^{2}$ Division of Infectious Diseases, Department of Medicine, Emory University School of Medicine, ${ }^{3}$ Department of Behavioral Sciences and Health Education, ${ }^{4}$ Hubert Department of Global Health, ${ }^{5}$ Ochsner Medical Center, Kenner, LA, ${ }^{6}$ Department of Biostatistics and Bioinformatics, Rollins School of Public Health, Emory University, Atlanta, GA, ${ }^{7}$ Department of Medicine, University of Arizona, Tucson, AZ, ${ }^{8}$ Division of Gynecologic Oncology, Department of Obstetrics and Gynecology, Emory University School of Medicine, Atlanta GA, USA
Correspondence: Lisa Flowers Division of Gynecologic Oncology, Department of Obstetrics and Gynecology, Emory University School of Medicine, 69 Jesse Hill Jr Drive, 4th Floor, Atlanta, GA 30303, USA

$\mathrm{Tel}+\mathrm{I} 4042518817$

Fax + I 404778 I 382

Email Iflowe2@emoryhealthcare.org
Background: This is a Phase I trial demonstrating safety and tolerability of intravaginal curcumin for future use in women with cervical neoplasia.

Objective: The objective of this study was to assess the safety, tolerability, and pharmacokinetics of intravaginal curcumin in healthy women.

Study design: We conducted a $3+3$ dose-escalation Phase I trial in a group of women aged 18-45 years. Thirteen subjects were given one of four doses of curcumin powder $(500 \mathrm{mg}$, $1,000 \mathrm{mg}, 1,500 \mathrm{mg}$, and 2,000 mg) packed in gelatin capsules, which was administered intravaginally daily for 14 days. The primary end point for this study was safety based on severe adverse events regarding laboratory toxicity, clinical findings, and colposcopic abnormalities. We administered an acceptability questionnaire to assess product experience and attributes.

Results: No dose-limiting toxicities ( $0 / 13$ ) were experienced (95\% confidence interval: $0.0 \%-$ $22.8 \%$ ) in this study. The pharmacokinetics data demonstrated that curcumin and curcumin conjugates were not measurable in the serum and negligible in the urine of the study participants. Although 23 adverse events occurred during the course of the trial, all events were grade I based on the National Cancer Institute Common Terminology Criteria for Adverse Events Version 4.0 and were resolved by the end of the study in an average of 9 days. Fifty-six percent of the adverse events were related to the study drug, which included genital pruritus ( $23 \%$ of subjects), vaginal discharge (100\%), vaginal dryness (15\%), abnormal prothrombin (23\%), and hypokalemia (8\%). Conclusion: Intravaginal curcumin was well tolerated by all subjects and safe. In this Phase I trial, there were no severe adverse events observed at any of the administered dose levels. All adverse events were grade I and did not result in early termination of the study. There was no evidence of systemic absorption or significant local absorption of intravaginally administered curcumin.

Keywords: cervix, curcumin, intravaginal, safety, tolerability, neoplasia

\section{Introduction}

Cervical cancer is the fourth most common cancer worldwide with $85 \%$ of the global burden occurring in developing countries. ${ }^{1}$ It is the leading cause of cancer-related deaths among women in East Africa, Central America, and Southeast Asia with an estimated 528,000 women developing the disease in 2012 and 266,000 deaths. ${ }^{1-6}$ Women in these countries are dying from the failure of treatment in a timely fashion to prevent the progression of cervical dysplasia to cancer. The lack of surgical equipment and trained clinicians who are able to perform routine surgical procedures (routine in most of the world) is one of the main causes. In addition, current treatment modalities for high-grade cervical intraepithelial neoplasia (CIN) are associated with complications such as preterm labor, preterm delivery, and cervical incompetence. ${ }^{6,7}$ The advent of a 
medical therapeutic agent that is economical and sustainable with a low side-effect profile may provide an alternative to surgical or ablative management of disease since there is normally a slow progression of high-grade CIN to cancer. This study explores the safety of such an agent: curcumin administered intravaginally in women.

Curcumin, a common ayurvedic medicinal agent, has been shown, in oral doses, to have anticancer activity and cause regression of premalignant lesions in several tissues including the cervix. ${ }^{8}$ Several studies have demonstrated that curcumin treatment alters human papillomavirus (HPV)-associated molecular pathways in cancer cells and suppresses cervical cancer growth by inhibiting the transcription of the oncoproteins of HPV16 and restoring the expression of tumor suppressor protein p53. ${ }^{9,10}$ In addition, it has been shown to downregulate E6 and E7 oncoproteins in human cancer cell lines, inhibit the expression of cancer promoting epidermal growth factor receptor, and induce p53 expression in HPV-infected cells. ${ }^{11}$

However, oral curcumin has poor bioavailability, limiting its ability to reach target tissues and organ systems at effective concentrations. ${ }^{12}$ However, in the past few years, some investigators have taken the approach of delivering curcumin via nanotechnology to increase its oral bioavailability in healthy subjects and patients with cancer; demonstration of effectiveness is still in its infancy. ${ }^{13,14}$ Thus, the development of a noninvasive medical intervention that involves the application of curcumin directly into the vagina presents a novel approach to the treatment of cervical dysplasia. Through an intravaginal route, dysplastic cervical cells would be directly targeted and the local dosing of curcumin would be easily monitored and controlled.

Therefore, the purpose of this study was to evaluate the safety, tolerability, and pharmacokinetics (PKs) of a potential medical therapeutic herb, curcumin, delivered intravaginally in women with no evidence of cervical intraepithelial lesions. We hypothesized that women would tolerate intravaginal curcumin with minimal to no adverse reactions, and that the PK analysis would demonstrate low serum bioavailability and low urinary excretion.

\section{Patients and methods}

\section{Institutional Review Board and Food and Drug Administration's investigational new drug application}

This study was granted approval from the Grady Health System Research Oversight Committee, Clinical Translational Research Committee, and the Emory institutional IRB Committee. The Food and Drug Administration's investiga- tional new drug number for this study is 103496 and the NCT number is 01035580 .

\section{Study sample}

Via convenience sampling strategies, we recruited 49 women who were willing to participate and subsequently assessed for the eligibility for this study. Following clinical screening of these potential participants, we excluded 36 women from the study due to their ineligibility based on the exclusion criteria. The 13 women who met the eligibility criteria were enrolled and provided their written informed consent to participate in the study (Figure 1).

Eligibility criteria for this study included: who 1) were identifying as female by birth (woman); 2) were in the age group of 18-45 years; 3 ) had a negative Pap test at screening; 4) reported regular monthly menses (every 21-35 days) or amenorrhea due to contraceptive use; 5) were willing to provide a male sexual partner notification consent if currently sexually active; and 6) could read and write in English and/or Spanish. All the study subjects were required to use contraception during the study.

Exclusion criteria included: who had 1) a history of having a total hysterectomy; 2) chronic medical conditions (including HIV, diabetes, hypertension) or immunologic disorders; 3) a history of cervical cancer; and 4) identified lacerations present on the cervix, vagina, or vulva at the time of screening.

\section{Methodological approach}

The study design used was a $3+3$ dose escalation approach (Figure 2). ${ }^{15}$ The maximum tolerated dose (MTD) was defined as the highest curcumin dose with acceptable side effects or dose-limiting toxicities (DLTs). For this study, the MTD was defined as the highest curcumin dose level at which $\leq 1 / 6$ patients developed DLTs. We selected the doses based on Sabinsa, CURCUMIN C3 COMPLEX ${ }^{\circledR}$ use in several clinical trials of which the curcumin is formulated into $500 \mathrm{mg}$ capsules. ${ }^{16}$ Due to the safety concerns, we started with the lowest dose and selected an upper bound of 2,000 mg expecting that would be the highest tolerable dose based on the information provided by the consulting gynecologists. The four capsules of $500 \mathrm{mg}$ would reach the $2,000 \mathrm{mg}$ dose. More than $90 \%$ of the gynecologists we surveyed prior to the clinical trial inception reported concern about patient comfort and compliance with greater than four capsules.

DLT was defined as any event related to the study drug, curcumin, based on the National Cancer Institute Common Terminology Criteria for Adverse Events Version 4.0 as category grade II or grade III or grade I lasting longer than 

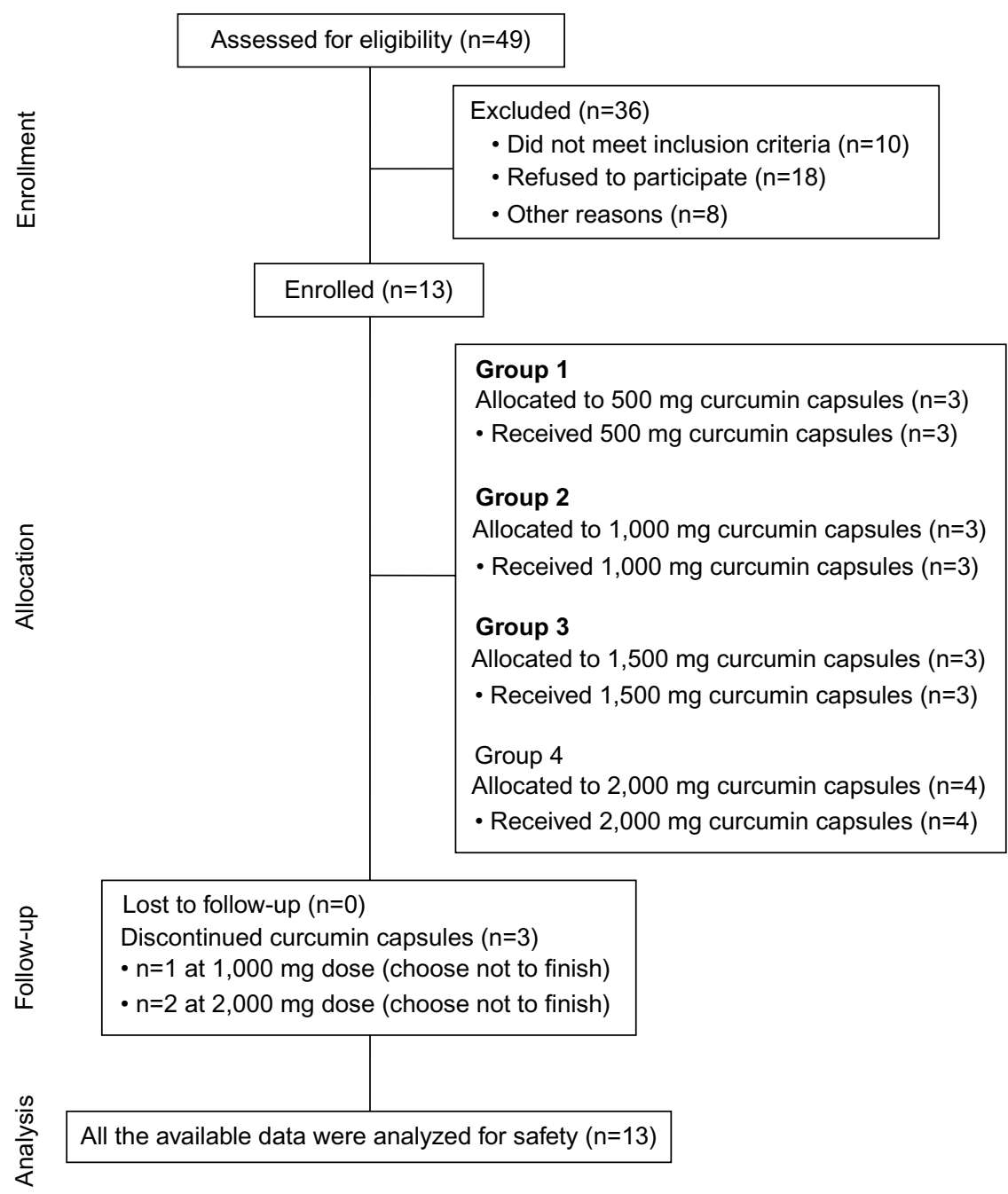

Figure I Study flow diagram.

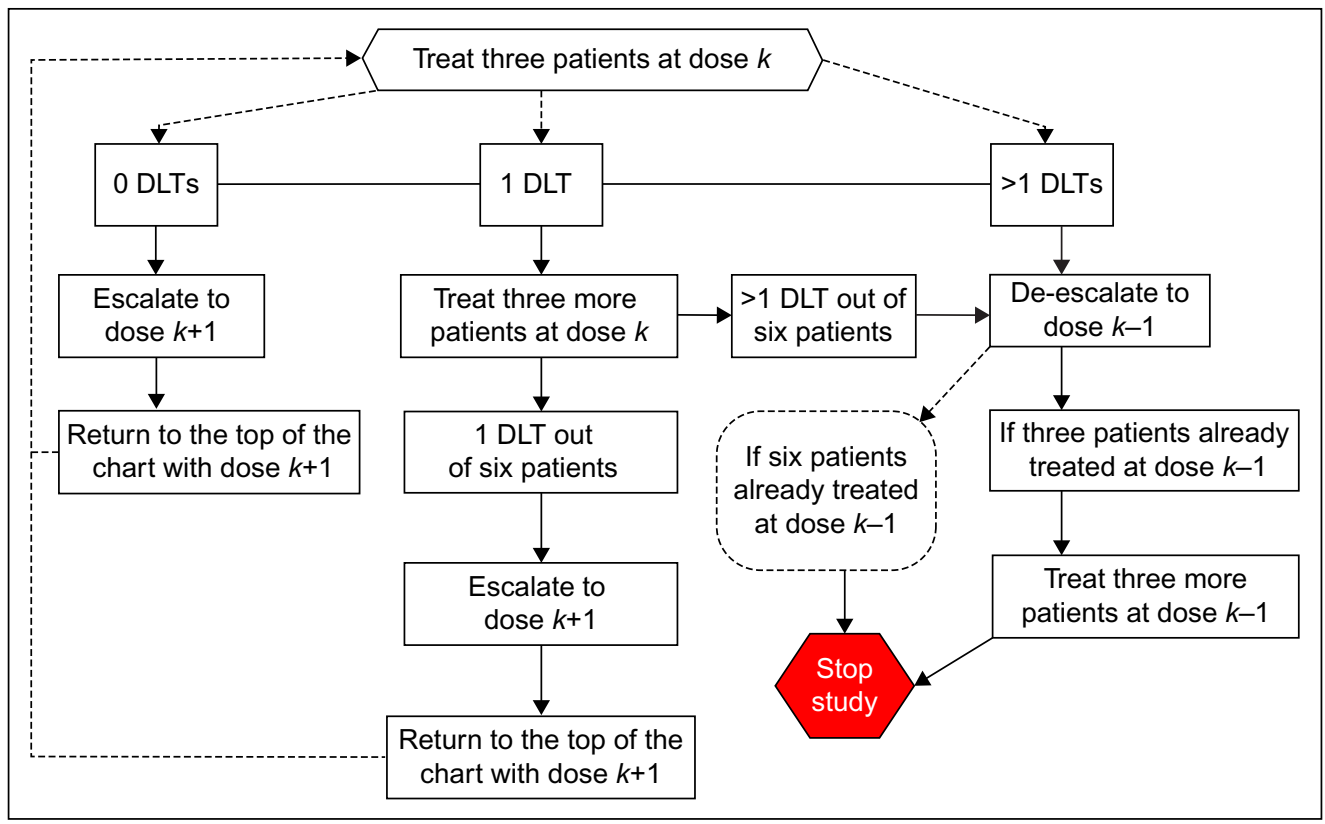

Figure 2 Traditional $3+3$ dose escalation study design.

Notes: $k$ indicates current dose examining throughout the study, $k+l$ indicates the dose higher than the current dose, $k-l$ indicates the dose lower than the current dose. Garrett-Mayer E, Clinical Trials, Vol 3(I), pages 57-7I, Copyright @ 2006 . Adapted by permission of SAGE Publications, Ltd. ${ }^{15}$

Abbreviation: DLT, dose-limiting toxicity. 
2 weeks in duration. DLT was the primary end point to be summarized with a proportion and $95 \%$ confidence interval (CI). For this reason, we did not calculate sample sizes and did not perform any inference tests. As is standard for a Phase I trial, the study had a very small sample size and is descriptive (by design).

\section{Study procedures}

In this trial, three subjects were to be treated at the lowest dose: $500 \mathrm{mg}$ curcumin capsules inserted intravaginally every day for 14 days. If one DLT was observed at $500 \mathrm{mg}$, then three more subjects were to be treated at $500 \mathrm{mg}$. If no DLT occurred in the first cohort of three subjects, then the three new subjects would proceed to insert 1,000 mg of curcumin intravaginally every day for 14 days. The dose escalation should continue per protocol until reaching the MTD.

The study drug, CURCUMIN C3 COMPLEX ${ }^{\circledR}$ Powder/ Curcuma longa (turmeric), was packaged in orange-colored gelatin capsules, size 0 , from Capsuline $\mathrm{R}$ and was supplied by the Sabinsa corporation at no cost. The study drug was free to all the study participants. Each gelatin capsule contained $500 \mathrm{mg}$ of CURCUMIN C3 COMPLEX ${ }^{\circledR}$. The capsules were placed in a carefully labeled opaque container and maintained at room temperature.
The initial screening of interested study participants was completed by a study nurse. On day 0 (enrollment visit), each participant had a clean catch urine analysis, hematology and chemistry 8 panel, and speculum/pelvic examination by a study clinician. Predose plasma and urine samples were collected for PK studies to evaluate the local absorption. The level of curcumin absorbed in the cervical tissues was not performed in this study, and it will be evaluated in the future studies. Wet prep was completed to test vaginal $\mathrm{pH}$ and ascertain the presence of candida, bacterial vaginosis, and trichomonas. A vaginal smear was air-dried for Gram's staining for Nugent's score and Ansel's criteria and used to diagnosis bacterial vaginosis. The colposcopy examination of the vulva, vagina, and cervix was conducted by qualified women's health clinicians. The colposcopic findings were recorded in a study chart, and the colposcope digital images were recorded and stored in a secured imaging database. Colposcopy was also completed on day 7 and day 14 of the study. The clinical and laboratory procedures are described in Table 1.

After completing 7 days of intravaginal applications of curcumin (day 7), each participant was admitted overnight to the Grady satellite of the Atlanta Clinical and Translational Science Institute Clinical Integrated Network for serial blood

Table I Clinical and laboratory procedures performed in the dose-escalation study of intravaginal curcumin in healthy women

\begin{tabular}{|c|c|c|c|c|}
\hline Clinical procedure & Screening & Day 0: enrollment & $\begin{array}{l}\text { Day 7: intravaginal } \\
\text { insertion }\end{array}$ & $\begin{array}{l}\text { Day 14: intravaginal } \\
\text { insertion }\end{array}$ \\
\hline Written informed consent & $\mathrm{x}$ & & & \\
\hline $\begin{array}{l}\text { Medical history, physical examination, demographic, and } \\
\text { clinical questionnaire }\end{array}$ & $\mathrm{x}$ & & & \\
\hline N. gonorrheae and C. trachomatis testing & $\mathrm{x}$ & & & \\
\hline Pap test and HPV testing & $x$ & & & \\
\hline $\begin{array}{l}\text { Urine sample collection for urinalysis at all visits; } \mathrm{hCG} \text { and } \\
\text { urine toxicology screen at screening only }\end{array}$ & $\mathrm{x}$ & $\mathrm{x}$ & $\mathrm{x}$ & $\mathrm{X}$ \\
\hline $\begin{array}{l}\text { Blood sample collection for HIV EIA and Western blot, } \\
\text { RPR }\end{array}$ & $\mathrm{x}$ & & & \\
\hline Blood sample collection for CBC, chemistry, PT/PTT & $\mathrm{x}$ & $\mathrm{X}$ & $x$ & $\mathrm{X}$ \\
\hline $\begin{array}{l}\text { Blood sample collection for plasma PK level and urine } \\
\text { drug studies }\end{array}$ & & & $x$ & \\
\hline $\begin{array}{l}\text { Pelvic examination, wet mount, vaginal pH, Gram stain, } \\
\mathrm{KOH} \text {, whiff test }\end{array}$ & $\mathrm{X}$ & $\mathrm{X}$ & $\mathrm{X}$ & $\mathrm{X}$ \\
\hline Colposcopy (day 0,7 , and I4 only) & & $\mathrm{X}$ & $\mathrm{X}$ & $\mathrm{X}$ \\
\hline Instruct on product insertion/observe first insertion & & $x$ & & \\
\hline Distribute study product & & $\mathrm{X}$ & $\mathrm{X}$ & \\
\hline Review study diary (day 7 and 14 ) & & & $\mathrm{X}$ & $\mathrm{X}$ \\
\hline Record number of returned gelatin capsules & & & $x$ & $x$ \\
\hline Complete data collection form & $\mathrm{x}$ & $\mathrm{X}$ & $\mathrm{x}$ & $x$ \\
\hline Acceptability questionnaire and focus group & & & & $x$ \\
\hline
\end{tabular}

Abbreviations: CBC, complete blood count; C. trachomatis, Chlamydia trachomatis; EIA, enzyme-linked immunosorbent assay; HPV, human papillomavirus; N. gonorrheae, Neisseria gonorrheae; PK, pharmacokinetic; PT, prothrombin; PTT, partial thromboplastin time; RPR, rapid plasma reagin. 
and urine sampling to study the PK of intravaginal curcumin. Based on the previous studies using similar intravaginal products, the expected steady state of drug absorption should have been achieved by day 7 . Any symptoms described by the participant since day 0 of the trial were transcribed into the participant's record. Vital signs, hematology and chemistry 8 panel, speculum examination with colposcopy, wet prep, and a Gram stain were collected.

At the completion of the study, patients' study diaries were reviewed to ascertain compliance and to discuss the adverse side effects. The remaining study capsules were counted and compared with the patient's study diary and report.

For pharmacokinetic sample collection, an indwelling foley catheter was inserted immediately after colposcopic examination to avoid contamination and to allow easy collection of urine samples. Intravenous access was obtained and left in place for serial blood draws. Quality trained Clinical Integrated Network personnel recorded the time of dosing and postdose blood draws at the following times: 0 hour, 0.25 hours, 0.5 hours, 1 hour, 1.5 hours, 2 hours, 3 hours, 4 hours, 5 hours, 6 hours, 8 hours, and 12 hours. The collected blood was centrifuged at 3,000 rpm for 10 minutes, and the serum was separated and kept frozen until PK analysis. Urine samples were collected at the same time points as the blood draws from the foley catheter. The catheter was completely emptied after each sampling. Urine volume for each collection was recorded, and aliquots of $2 \mathrm{~mL}$ were stored and frozen until PK analysis.

For pharmacokinetic analysis, plasma and urine concentrations of curcumin and curcumin glucuronide/sulfate conjugates were quantified by liquid chromatography coupled with tandem mass spectrometry. For the quantification of curcumin, aliquots of plasma or urine samples were spiked with the internal standard (honokiol) and extracted with ethyl acetate prior to liquid chromatography coupled with tandem mass spectrometry analysis. For the quantification of curcumin conjugates, aliquots of samples underwent enzymatic hydrolysis prior to ethyl acetate extraction. Chromatographic separation was achieved on a $\mathrm{C} 18$ column with a gradient of water and acetonitrile consisting of $0.3 \%$ formic acid. Curcumin and the internal standard were detected in the selected reaction monitoring mode utilizing negative electrospray ionization. Linear calibration curve was established over a curcumin concentration range of $0.5-500 \mathrm{ng} / \mathrm{mL}$ when $0.5 \mathrm{~mL}$ of plasma or urine was used.

On day 14 of treatment, vital signs, blood work, speculum examination, wet prep, Gram stain, and colposcopy were completed. The participant's study diary was reviewed to ascertain the compliance and inquire about the adverse side effects. These data were recorded in the patient's chart. Any remaining capsules were counted and compared with the patient's study diary. All the study participants were then administered an acceptability questionnaire to complete at the end of their study participation on day 14 .

Outcome measures for safety data were based on severe adverse effects regarding laboratory toxicity, severe colposcopic abnormalities, and severe adverse clinical findings. Adverse side effects were coded, and the percentage of patients experiencing that event was recorded. The clinical symptoms measured included pelvic pain, genital pruritus, genital pain, vaginal discharge, perianal ulcers, vaginal dryness, vaginitis, breakthrough bleeding, and decreased libido. DLTs were summarized with a 95\% CI using Wilson's method for a single sample. ${ }^{17}$

Colposcopic findings (present or absent) were described for each dose at baseline, day 0 , day 7 , and day 14 .

\section{Acceptability assessment}

Study materials were developed in English and Spanish. Bilingual clinical staff and behavioral scientists reviewed these documents to ensure their adequate readability and item comprehension prior to administration. We determined that the Flesch-Kincaid reading score met the acceptable criteria of sixth to eighth grade reading level for our target population. ${ }^{18,19}$

Acceptability was assessed by asking women if they were comfortable using curcumin capsules and if they experienced any problems with the product. In addition to the selected acceptability correlates, the questionnaire included scale items designed to measure psychosocial indicators of attitudes and perceptions surrounding their curcumin experience such as if they noticed curcumin after insertion and after sex. Each scale item was measured by a 3-5-point Likert scale (eg, 1, strongly disagree to 5, strongly agree), which was designed to assign meaningful values to an underlying continuum of ratings. ${ }^{20}$

\section{Results}

A total of 13 women meeting the eligibility criteria were enrolled and completed the dose-escalation trial. The demographic profile of enrolled subjects was as follows: Hispanic/ Latino (15.4\%), Asian (7.7\%), African American (46.2\%), and Caucasian (30.8\%); the mean age at the enrollment was 28.8 years. Three of the subjects had no partners, six were living with a partner, and four were not living with their partners (Table 2). 
Table 2 Baseline characteristics of healthy women enrolled in the study of intravaginal curcumin, overall and by curcumin dose ( $\mathrm{n}=13$ )

\begin{tabular}{|c|c|c|c|c|c|}
\hline Characteristics & Overall $(n=13)$ & $500 \mathrm{mg}(\mathrm{n}=3)$ & $1,000 \mathrm{mg}(\mathrm{n}=3)$ & $1,500 \mathrm{mg}(\mathrm{n}=3)$ & $2,000 \mathrm{mg}(\mathrm{n}=4)$ \\
\hline \multicolumn{6}{|l|}{ Ethnicity } \\
\hline Hispanic & $2 / 13(15.4 \%)$ & $1 / 3(33.3 \%)$ & $\mathrm{I} / 3(66.7 \%)$ & $0 / 3(0.0 \%)$ & $0 / 4(0.0 \%)$ \\
\hline \multicolumn{6}{|l|}{ Race } \\
\hline Asian & $1 / 13(7.7 \%)$ & $\mathrm{I} / 3(33.3 \%)$ & $0 / 3(0.0 \%)$ & $0 / 3(0.0 \%)$ & $0 / 4(0.0 \%)$ \\
\hline Black & $6 / 13(46.2 \%)$ & $0 / 3(0.0 \%)$ & $1 / 3(33.3 \%)$ & $2 / 3(66.7 \%)$ & $3 / 4(75.0 \%)$ \\
\hline Other & $2 / 13(15.4 \%)$ & $1 / 3(33.3 \%)$ & $1 / 3(33.3 \%)$ & $0 / 3(0.0 \%)$ & $0 / 4(0.0 \%)$ \\
\hline White & $4 / 13(30.8 \%)$ & $\mathrm{I} / 3(33.3 \%)$ & $1 / 3(33.3 \%)$ & $\mathrm{I} / 3(33.3 \%)$ & $\mathrm{I} / 4(25.0 \%)$ \\
\hline \multicolumn{6}{|l|}{ Partner status } \\
\hline No partner & $3 / 13(23.1 \%)$ & $0 / 3(0.0 \%)$ & $\mathrm{I} / 3(33.3 \%)$ & $\mathrm{I} / 3(33.3 \%)$ & $\mathrm{I} / 4(25.0 \%)$ \\
\hline Living with a partner & $6 / 13(46.2 \%)$ & $1 / 3(33.3 \%)$ & $1 / 3(33.3 \%)$ & $1 / 3(33.3 \%)$ & $3 / 4(75.0 \%)$ \\
\hline Not living with a partner & $4 / 13(30.8 \%)$ & $2 / 3(66.7 \%)$ & $\mathrm{I} / 3(33.3 \%)$ & $\mathrm{I} / 3(33.3 \%)$ & $0 / 4(0.0 \%)$ \\
\hline Age, mean (SD) & $28.8(7.6)$ & $27.2(10.4)$ & $28.2(6.2)$ & $23.8(2.9)$ & $34.0(7.9)$ \\
\hline
\end{tabular}

Note: Data shown as number (\%) or mean (SD).

The first study subject of the $2,000 \mathrm{mg}$ dose had only $2 \mathrm{~mL}$ of serum and urine collected at each time point during the PK component of the study. Therefore, an additional study subject was added in the 2,000 $\mathrm{mg}$ dose to assure adequate collection of serum and urine for the required 12 subjects for the PK analysis. The number of subjects starting therapy at each dose is shown in Figure 1. No DLTs were observed at $500 \mathrm{mg}, 1,000 \mathrm{mg}, 1,500 \mathrm{mg}$, and 2,000 mg. An MTD was not identified. The study was stopped at $2,000 \mathrm{mg}$ due to funding limitations.

\section{Pelvic examination}

No pelvic examination abnormalities were found with the exception of one vulvar abnormality and one cervical abnormality present since the time of screening. These abnormalities did not exclude either of the patients from the enrollment. Pelvic examination test results found one subject (dose: 1,500 mg) with an abnormal wet mount consistent with bacterial vaginosis at day 7 which was not treated and resolved spontaneously by day 14 . Two subjects at day 0 (dose: $1,000 \mathrm{mg}$ and 1,500 mg) had yeast detected on $\mathrm{KOH}$ slide. However, these subjects denied clinical symptoms and were not treated. On day 7 , no evidence of yeast was found on the examination for both subjects. On day 14, two subjects were found to have yeast vaginitis (dose: $500 \mathrm{mg}$ and 1,500 mg). These two subjects did not exhibit any clinical symptoms when contacted after 48 hours of completing the study. The most common urogenital symptoms found during the pelvic examination were genital pruritis, vaginal discharge, and vaginal dryness.

\section{Genital pruritis}

No subjects reported genital pruritis during the screening and day 0 visits. However, three subjects (23\%) reported pruritis on day 7; one at the $500 \mathrm{mg}$ dose and the remaining two subjects at the 1,500 $\mathrm{mg}$ dose. One subject (dose: 1,500 mg) also had genital pruritis at day 14 .

\section{Vaginal discharge}

One subject presented with vaginal discharge at day 0 , upon the application of first dose (dose: $1,000 \mathrm{mg}$ ). All the subjects reported vaginal discharge on day 7 and day 14 .

\section{Vaginal dryness}

Two subjects (15.4\%) reported vaginal dryness at day 7 and day 14 . The subjects who reported vaginal dryness at day 7 were taking the $500 \mathrm{mg}$ and $1,500 \mathrm{mg}$ doses. The subjects reporting vaginal dryness at day 14 were taking the $1,000 \mathrm{mg}$ and $1,500 \mathrm{mg}$ dose.

\section{Colposcopy examination}

No abnormal colposcopy results were found during the course of the study. Colposcopic findings investigated were erythema, edema, leukoplakia, petechiae, ecchymosis, peeling, ulceration, abrasion, and laceration.

\section{Laboratory results}

There were no abnormal laboratory results greater than grade I abnormality. Positive dipstick urinalysis results were found in one subject at screening (dose: $500 \mathrm{mg}$ ), two subjects at day 0 (dose: $500 \mathrm{mg}$ ), and one subject at day 14 (dose: $1,000 \mathrm{mg}$ ). No study subject was diagnosed with a urinary tract infection. Three subjects $(25 \%)$ had an intermediate Nugent score at day 7, one subject at the $500 \mathrm{mg}$ dose, and two at the $1,500 \mathrm{mg}$ dose. Three subjects (23.1\%) also had an intermediate result at day 14 (one subject each at the $500 \mathrm{mg}$, $1,500 \mathrm{mg}$, and 2,000 $\mathrm{mg}$ dose). No study subjects were found to have a Nugent score on Gram stain eligible for bacterial vaginosis (Nugent score $>7$ ). 


\section{Adverse events}

Twenty-three adverse events occurred in 13 subjects during the course of the trial, six events in each of the following groups: $500 \mathrm{mg}$ dose, $1,500 \mathrm{mg}$ dose, and 2,000 $\mathrm{mg}$ dose, and five events in the $1,000 \mathrm{mg}$ dose group (Table 3 ). The adverse events fell into five categories: genital pruritis $(23 \%$ of subjects), vaginal discharge (100\%), vaginal dryness $(23 \%)$, abnormal prothrombin (23\%), and hypokalemia (8\%). All events were grade I, and no DLTs were experienced. Fiftysix percent of the events were definitely related to the study drug. None of the events had any implication for the study, and no events required additional action. All events were resolved by the end of the study in an average of 8.7 days.

\section{Pharmacokinetic data}

PK analysis was performed only in the 2,000 mg study population $(n=4)$. There were no detectable levels of curcumin or its conjugated metabolites in any of the serum samples collected from the 2,000 $\mathrm{mg}$ dose group. However, curcumin and its metabolites were detectable in urine collected from the 2,000 $\mathrm{mg}$ dose group. The total amount of curcumin and its conjugated metabolites in urine collected up to 12 hours post-dose was $0-17.5 \mu \mathrm{g}$ and $0-0.5 \mu \mathrm{g}$, respectively, $<0.001 \%$ of the dose applied.

\section{Acceptability questionnaire data}

Fifty-four percent $(n=7 / 13)$ of the subjects rated the intravaginal application of curcumin as easy or very easy, regardless of the dosage (Table 4). Seventy-seven percent of the study subjects $(n=10 / 13)$ denied any problems with the product. The majority $(69 \%, n=9)$ of the study participants denied any symptoms of irritation. However, $84 \%$ of women $(n=11 / 13)$ disliked the color of the curcumin, and the majority found it was too messy. All the study subjects agreed they would recommend this product to women as a way to prevent cervical precancerous disease from turning into cancer, if approved as safe and effective $(100 \%, \mathrm{n}=13)$.

\section{Discussion}

Curcumin is an inexpensive naturally occurring agent which employs multiple mechanisms of action that can alter HPVassociated molecular pathways. ${ }^{9-11}$ Curcumin appears to target key cell signaling pathways at multiple levels including oncogenes (E6 and E7), inflammatory enzymes (COX-2), and transcription factors (NF-k $\beta$ and AP-1). ${ }^{21-24}$ In high-risk HPV cervical cell lines, it induces apoptosis by primarily inhibiting the expression of E7. ${ }^{10}$ In light of high-risk HPV subtypes, 16 and 18 being largely responsible for high-grade cellular transformation in the cervix. Curcumin's potential role in the prevention of cervical cancer would be its ability to inhibit the expression of HPV oncogenes E6/E7, leading to the restoration of $\mathrm{p} 53$ and $\mathrm{Rb}$ tumor suppressor gene expression. ${ }^{9,10,25}$

In this trial, we sought to evaluate the safety, tolerability, and PKs of intravaginal curcumin in healthy young women. The results of this dose-escalation trial demonstrated safety and tolerability up to a maximum dose of 2,000 $\mathrm{mg}$ per day for a 14-day treatment. We observed no clinical or hematologic toxicities higher than grade I during the trial. There were no pelvic or colposcopic abnormalities caused by the study drug during the trial period. The PK data demonstrated that curcumin and its conjugates were not measurable in the serum and negligible in the urine of the study participants. Similar adverse events such as vulvovaginal pruritus were also seen in recent publications using curcumin cream for HPV infection of the cervix. ${ }^{26}$

Our study identified that the most common symptom observed was vaginal discharge that commenced following the intravaginal insertion. This discharge persisted with continued usage of the study drug in which the participants noted as an inconvenience. Yet, the vaginal

Table 3 Frequency of adverse events and the frequency and percentage of healthy women with adverse events found during pelvic examination or laboratory toxicities during the 2 weeks of curcumin treatment

\begin{tabular}{|c|c|c|c|c|c|}
\hline \multirow[t]{2}{*}{ Adverse event } & Overall $(n=13)$ & $500 \mathrm{mg}(\mathrm{n}=3)$ & $1,000 \mathrm{mg}(\mathrm{n}=3)$ & $1,500 \mathrm{mg}(\mathrm{n}=3)$ & $2,000 \mathrm{mg}(\mathrm{n}=4)$ \\
\hline & AE (Pat) \% & AE (Pat) \% & AE (Pat) \% & AE (Pat) \% & AE (Pat) \% \\
\hline $\mathrm{DLT}^{\mathrm{a}}$ & 0 (0) $0.0 \%$ & 0 (0) $0.0 \%$ & $0(0) 0.0 \%$ & $0(0) 0.0 \%$ & 0 (0) $0.0 \%$ \\
\hline Genital pruritic & 4 (3) $23.1 \%$ & 2 (I) $33.3 \%$ & $0(0) 0.0 \%$ & 2 (2) $66.7 \%$ & $0(0) 0.0 \%$ \\
\hline Vaginal discharge & 13 (13) $100 \%$ & 3 (3) $100 \%$ & $3(3) 100 \%$ & $3(3) 100 \%$ & $4(4) 100 \%$ \\
\hline Vaginal dryness & 2 (2) $15.4 \%$ & I (I) $33.3 \%$ & 0 (0) $0.0 \%$ & I (I) $33.3 \%$ & 0 (0) $0.0 \%$ \\
\hline Abnormal $\mathrm{PT}^{\mathrm{b}}$ & 3 (3) $23.1 \%$ & $0(0) 0.0 \%$ & 2 (2) $66.7 \%$ & 0 (0) $0.0 \%$ & I (I) $25.0 \%$ \\
\hline Hypokalemiac $^{c}$ & I (I) $7.7 \%$ & 0 (0) $0.0 \%$ & 0 (0) $0.0 \%$ & $0(0) 0.0 \%$ & I (I) $25.0 \%$ \\
\hline
\end{tabular}

Notes: aDLT was defined as any event related to the study drug "curcumin" based on the National Cancer Institute CTCAE Version 4.0 as category grade II or grade III or grade I lasting longer than 2 weeks in duration. 'Defined as $>1.0 \times$ ULN. 'Defined as $5.0 \mathrm{mEq} / \mathrm{L}$ or higher.

Abbreviations: AE, adverse event; CTCAE, Common Terminology Criteria for Adverse Events; DLT, dose-limiting toxicity; Pat, patients; PT, prothrombin; ULN, upper limit of normal. 
Table 4 Results from acceptability questionnaire administered to 13 healthy women after using intravaginal curcumin for 2 weeks, overall and by curcumin dose

\begin{tabular}{|c|c|c|c|c|c|}
\hline Questionnaire responses & Overall & $500 \mathrm{mg}$ & I,000 mg & I,500 mg & $2,000 \mathrm{mg}$ \\
\hline & n (\%) & n (\%) & n (\%) & n (\%) & n (\%) \\
\hline Noticed curcumin powder after insertion & I I/I 3 (84.6\%) & $2 / 3(66.7 \%)$ & $3 / 3(100 \%)$ & $3 / 3(100 \%)$ & $3 / 4(75.0 \%)$ \\
\hline Noticed curcumin powder after sex & $3 / 13(23.1 \%)$ & I/3 (33.3\%) & $1 / 3(33.3 \%)$ & $0 / 3(0.0 \%)$ & $\mathrm{I} / 4(25.0 \%)$ \\
\hline Had problems with the product & $3 / 13(23.1 \%)$ & I/3 (33.3\%) & I/3 (33.3\%) & $0 / 3(0.0 \%)$ & $\mathrm{I} / 4(25.0 \%)$ \\
\hline Curcumin powder gave symptoms of irritation & $4 / 13(30.8 \%)$ & $\mathrm{I} / 3(33.3 \%)$ & I/3 (33.3\%) & $2 / 3(66.7 \%)$ & $0 / 4(0.0 \%)$ \\
\hline Could smell the curcumin powder & $2 / 13(15.4 \%)$ & $0 / 3(0.0 \%)$ & $0 / 3(0.0 \%)$ & $\mathrm{I} / 3(33.3 \%)$ & $\mathrm{I} / 4(25.0 \%)$ \\
\hline \multicolumn{6}{|l|}{ Describe the smell of the curcumin powder } \\
\hline Neutral & $12 / 13(92.3 \%)$ & $3 / 3(100 \%)$ & $3 / 3(100 \%)$ & $3 / 3(100 \%)$ & $3 / 4(75.0 \%)$ \\
\hline Unpleasant & $\mathrm{I} / \mathrm{I} 3(7.75)$ & $0 / 3(0.0 \%)$ & $0 / 3(0.0 \%)$ & $0 / 3(0.0 \%)$ & $\mathrm{I} / 4(25.0 \%)$ \\
\hline \multicolumn{6}{|l|}{ Rate the curcumin powder's color } \\
\hline Neutral & $2 / 13(15.4 \%)$ & $0 / 3(0.0 \%)$ & $0 / 3(0.0 \%)$ & $\mathrm{I} / 3(33.3 \%)$ & $\mathrm{I} / 4(25.0 \%)$ \\
\hline Disliked & $4 / 13(30.85)$ & $2 / 3(66.75)$ & $0 / 3(0.0 \%)$ & $\mathrm{I} / 3(33.3 \%)$ & $\mathrm{I} / 4(25.0 \%)$ \\
\hline Disliked a lot & $7 / 13(53.9 \%)$ & $\mathrm{I} / 3(33.3 \%)$ & $3 / 3(100 \%)$ & I/3 (33.3\%) & $2 / 4(50.0 \%)$ \\
\hline \multicolumn{6}{|l|}{ Curcumin stained my underwear } \\
\hline Strongly agree & $9 / 13(69.2 \%)$ & $3 / 3(100 \%)$ & $3 / 3(100 \%)$ & $0 / 3(0.0 \%)$ & $\mathrm{I} / 4(25.0 \%)$ \\
\hline Somewhat agree & $4 / 13(30.8 \%)$ & $2 / 3(66.7 \%)$ & $0 / 3(0.0 \%)$ & $1 / 3(33.3 \%)$ & $\mathrm{I} / 4(25.0 \%)$ \\
\hline \multicolumn{6}{|l|}{ I am comfortable using curcumin powder } \\
\hline Strongly agree & $4 / 13(30.9 \%)$ & $\mathrm{I} / 3(33.3 \%)$ & $0 / 3(0.0 \%)$ & $2 / 3(66.7 \%)$ & $\mathrm{I} / 4(25.0 \%)$ \\
\hline Somewhat agree & $5 / 13(38.5 \%)$ & $\mathrm{I} / 3(33.3 \%)$ & $1 / 3(33.3 \%)$ & I/3 (33.3\%) & $2 / 4(50.0 \%)$ \\
\hline Neutral & $2 / 13(15.4 \%)$ & I/3 (33.3\%) & $1 / 3(33.3 \%)$ & $0 / 3(0.0 \%)$ & $0 / 4(0.0 \%)$ \\
\hline Somewhat disagree & $2 / 13(15.4 \%)$ & $0 / 3(0.0 \%)$ & $1 / 3(33.3 \%)$ & $0 / 3(0.0 \%)$ & $\mathrm{I} / 4(25.0 \%)$ \\
\hline \multicolumn{6}{|c|}{ Rate the ease of insertion of the curcumin gelatin capsules } \\
\hline Very easy & $3 / 13(23.1 \%)$ & $0 / 3(0.0 \%)$ & $1 / 3(33.3 \%)$ & I/3 (33.3\%) & $\mathrm{I} / 4(25.0 \%)$ \\
\hline Easy & $4 / 13(30.8 \%)$ & $0 / 3(0.0 \%)$ & $2 / 3(66.7 \%)$ & $0 / 3(0.0 \%)$ & $2 / 4(50.0 \%)$ \\
\hline Neutral & $4 / 13(30.8 \%)$ & $2 / 3(66.7 \%)$ & $0 / 3(0.0 \%)$ & $1 / 3(33.3 \%)$ & $\mathrm{I} / 4(25.0 \%)$ \\
\hline Difficult & $2 / 13(15.4 \%)$ & $\mathrm{I} / 3(33.3 \%)$ & $0 / 3(0.0 \%)$ & $\mathrm{I} / 3(33.3 \%)$ & $0 / 4(0.0 \%)$ \\
\hline \multicolumn{6}{|l|}{ The curcumin powder was too messy } \\
\hline Strongly agree & $6 / 13(46.2 \%)$ & $1 / 3(33 . \%)$ & $3 / 3(100 \%)$ & $0 / 3(0.0 \%)$ & $2 / 4(50.0 \%)$ \\
\hline Somewhat agree & $5 / 13(38.5 \%)$ & $2 / 3(66.7 \%)$ & $0 / 3(0.0 \%)$ & $3 / 3(100 \%)$ & $0 / 4(0.0 \%)$ \\
\hline Somewhat disagree & $1 / 13(7.7 \%)$ & $0 / 3(0.0 \%)$ & $0 / 3(0.0 \%)$ & $0 / 3(0.0 \%)$ & $\mathrm{I} / 4(25.0 \%)$ \\
\hline Strongly disagree & $1 / 13(7.7 \%)$ & $0 / 3(0.0 \%)$ & $0 / 3(0.0 \%)$ & $0 / 3(0.0 \%)$ & $\mathrm{I} / 4(25.0 \%)$ \\
\hline \multicolumn{6}{|c|}{ I felt the curcumin powder increased my sexual pleasure } \\
\hline Neutral & $7 / 13(53.9 \%)$ & $\mathrm{I} / 3(33.3 \%)$ & $2 / 3(66.7 \%)$ & $2 / 3(66.7 \%)$ & $2 / 4(50.0 \%)$ \\
\hline Somewhat disagree & $5 / 13(38.5 \%)$ & $2 / 3(66.7 \%)$ & $1 / 3(33.3 \%)$ & $1 / 3(33.3 \%)$ & $\mathrm{I} / 4(25.0 \%)$ \\
\hline Strongly disagree & $1 / 13(7.7 \%)$ & $0 / 3(0.0 \%)$ & $0 / 3(0.0 \%)$ & $0 / 3(0.0 \%)$ & $\mathrm{I} / 4(25.0 \%)$ \\
\hline
\end{tabular}

discharge resolved without intervention once the drug was discontinued. At the completion of the trial, all the participants agreed that the delivery of curcumin intravaginally at all the study protocol dosages was tolerable and that they would recommend it to women for the treatment of cervical disease.

The safety and tolerability of intravaginally administered curcumin for potential use in the treatment of women with cervical dysplasia are evidenced by this trial. The low costs of curcumin could make this medical therapy even more attractive in the US as well as developing and lowresource countries. Other studies are currently focused on the development and implementation of injectable medical therapies to treat high-grade cervical dysplasia. However, intravaginal curcumin capsules stored at room temperature may be more affordable than any injectable medication which may require expensive, specialized preparation and storage.

Although we were not able to measure the amount of drug absorbed locally by inserting the curcumin capsules intravaginally, colposcopic evaluations during the treatment course evidenced that the cervix was adequately coated with the active ingredient of the investigational drug (Figure 3 ). In addition, our patient population did not include women who were postmenopausal. Therefore, we were not able to observe whether this age group would have incured more vaginal dryness and pruritus. However, it is less likely that this age group will receive intravaginal curcumin for the treatment of cervical dysplasia in an effort to preserve fertility. They are more likely to be treated with surgical resection via loop electrical excisional procedure or hysterectomy for the management of their cervical dysplasia. 


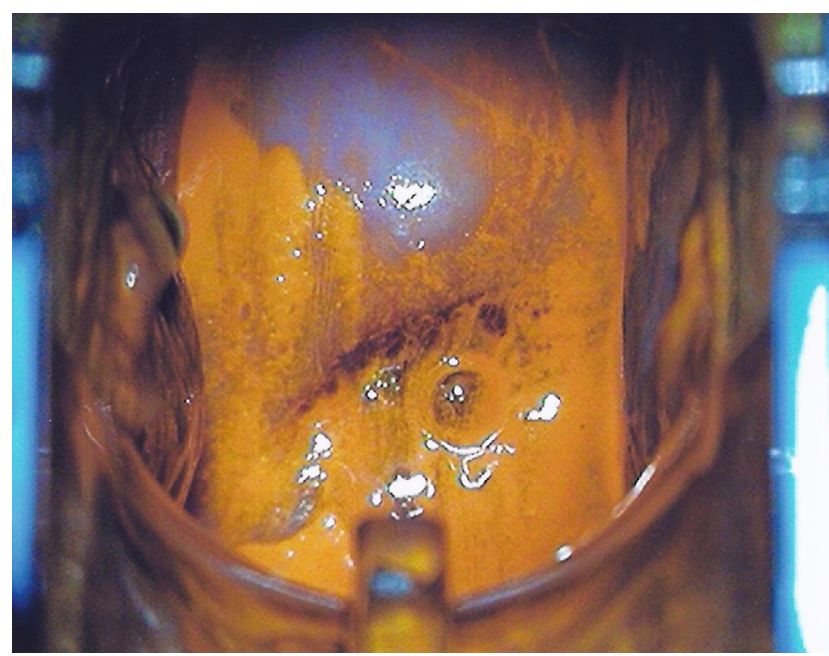

Figure 3 Intravaginal curcumin on the cervix.

\section{Limitations}

One of the limitations of this study was that the MTD was not reached and 2,000 $\mathrm{mg}$ is most likely an underestimation of the MTD. It may be prudent in the future trials to consider challenging this dosage especially for efficacy trials. A recent four-arm Phase II trial comparing vaginal Basant cream (curcumin based), curcumin capsules, vaginal placebo cream, and placebo capsules demonstrated higher HPV clearance rates in the Basant cream arm and the curcumin capsule arm compared with the placebo groups. ${ }^{26}$ The results of this trial show even more promise for the efficacy of curcumin given that the maximum dose used was only $500 \mathrm{mg}$ in the vaginal capsules. ${ }^{26}$ Our trial clearly demonstrates that the MTD can be upward of 2,000 $\mathrm{mg}$.

\section{Conclusion}

This Phase I study found that intravaginal curcumin application resulted in minimal side effects and a safe pharmacokinetic profile. Yet, the product will need to improve its product attributes (ie, color and messiness) to improve its acceptability profile. Such modifications may encourage its use as a potential treatment option for the treatment of cervical dysplasia. However, with its multitude of antiinflammatory and anti-carcinogenic properties, future clinical studies may reflect that curcumin is an ideal compound to use for the treatment of cervical dysplasia.

\section{Acknowledgments}

The following are sources of support: PHS Grant UL1 RR025008 from the Clinical and Translational Science Award program, National Institutes of Health, and National Center for Research Sources; Emory Medical Care Foundation
Grant 0369; Center for AIDS Research at Emory University (P30 AI050409); Emory URC Grant and in part by the CocaCola Enterprises Research Award, a philanthropic award provided by the Winship Cancer Institute of Emory University.

\section{Disclosure}

The authors report no conflicts of interest in this work.

\section{References}

1. Globocan (2012) [webpage on the Internet]. Cancer Fact Sheet. Cervical Cancer Incidence and Mortality Worldwide in 2012; Available from: http://globocan.iarc.fr/old/FactSheets/cancers/cervix-new.asp. Accessed June 9, 2016.

2. Di J, Rutherford S, Chu C. Review of the cervical cancer burden and population-based cervical cancer screening in China. Asian Pac $J$ Cancer Prev. 2015;16(17):7401-7407.

3. Garland SM, Bhatla N, Ngan HY. Cervical cancer burden and prevention strategies: Asia Oceania perspective. Cancer Epidemiol Biomarkers Prev. 2012;21(9):1414-1422.

4. Mvundura M, Tsu V. Estimating the costs of cervical cancer screening in high-burden Sub-Saharan African countries. Int J Gynaecol Obstet. 2014;126(2):151-155.

5. Waktola EA, Mihret W, Bekele L. HPV and burden of cervical cancer in East Africa. Gynecol Oncol. 2005;99(3 suppl 1):S201-S202.

6. Arbyn M, Castellsagué X, de Sanjosé S, et al. Worldwide burden of cervical cancer in 2008. Ann Oncol. 2011;22(12):2675-2686.

7. Kyrgiou M, Koliopoulos G, Martin-Hirsch P, Arbyn M, Prendiville W, Paraskevaidis E. Obstetric outcomes after conservative treatment for intraepithelial or early invasive cervical lesions: systematic review and meta-analysis. Lancet. 2006;367(9509):489-498.

8. Cheng AL, Hsu CH, Lin JK, et al. Phase I clinical trial of curcumin, a chemopreventive agent, in patients with high-risk or pre-malignant lesions. Anticancer Res. 2001;21(4B):2895-2900.

9. Maher DM, Bell MC, O’Donnell EA, Gupta BK, Jaggi M, Chauhan SC. Curcumin suppresses human papillomavirus oncoproteins, restores $\mathrm{p} 53, \mathrm{Rb}$, and PTPN13 proteins and inhibits benzo[a]pyrene-induced upregulation of HPV E7. Mol Carcinog. 2011;50(1):47-57.

10. Singh M, Singh N. Molecular mechanism of curcumin induced cytotoxicity in human cervical carcinoma cells. Mol Cell Biochem. 2009; 325(1-2):107-119.

11. Debata PR, Castellanos MR, Fata JE, et al. A novel curcumin-based vaginal cream Vacurin selectively eliminates apposed human cervical cancer cells. Gynecol Oncol. 2013;129(1):145-153.

12. Anand P, Kunnumakkara AB, Newman RA, Aggarwal BB. Bioavailability of curcumin: problems and promises. Mol Pharm. 2007;4(6): 807-818.

13. Kanai M, Imaizumi A, Otsuka Y, et al. Dose-escalation and pharmacokinetic study of nanoparticle curcumin, a potential anticancer agent with improved bioavailability, in healthy human volunteers. Cancer Chemother Pharmacol. 2012;69(1):65-70.

14. Kanai M, Otsuka Y, Otsuka K, et al. A phase I study investigating the safety and pharmacokinetics of highly bioavailable curcumin (Theracurmin $\left.{ }^{\circledR}\right)$ in cancer patients. Cancer Chemother Pharmacol. 2013;71(6):1521-1530.

15. Garrett-Mayer E. The continual reassessment method for dose-finding studies: a tutorial. Clin Trials. 2006;3(1):57-71.

16. Lao CD, Ruffin MT 4th, Normolle D, et al. Dose escalation of a curcuminoid formulation. BMC Complement Altern Med. 2006;6(1):10.

17. Altman D, Machin D, Bryant TN, Gardner MJ. Statistics with Confidence. 2nd ed. London: BMJ Books; 2000.

18. Davis TC, Mayeaux EJ, Fredrickson D, Bocchini JA Jr, Jackson RH, Murphy PW. Reading ability of parents compared with reading level of pediatric patient education materials. Pediatrics. 1994;93(3):460-468. 
19. Miller B, Bodie M. Determination of reading comprehension level for effective patient health-education materials. Nurs Res. 1994;43(2): $118-119$.

20. Meyers LS, Gamst G, Guarino AJ. Applied Multivariate Research: Design and Interpretation. Thousand Oaks: Sage Publications; 2006:722.

21. Divya C, Pillai M. Antitumor action of curcumin in human papillomavirus associated cells involves downregulation of viral oncogenes, prevention of NFkB and AP-1 translocation, and modulation of apoptosis. Mol Carcinog. 2006;45(5):320-332.

22. Prusty B, Das B. Constitutive activation of transcription factor AP-1 in cervical cancer and suppression of human papillomavirus (HPV) transcription and AP-1 activity in HeLa cells by curcumin. Int J Cancer. 2005;113(6):951-960.
23. Madden K, Flowers L, Salani R, et al. Proteomics-based approach to elucidate the mechanism of antitumor effect of curcumin in cervical cancer. Prostaglandins Leukot Essent Fatty Acids. 2009;80(1):9-18.

24. Joshi JV, Paradkar PH, Jagtap SS, Agashe SV, Soman G, Vaidya AB. Chemopreventive potential and safety profile of a Curcuma longa extract in women with cervical low-grade squamous intraepithelial neoplasia. Asian Pac J Cancer Prev. 2011;12(12):3305-3311.

25. Bosch FX, Lorincz A, Muñoz N, Meijer CJ, Shah KV. The causal relation between human papillomavirus and cervical cancer. J Clin Pathol. 2002;55(4):244-265.

26. Basu P, Dutta S, Begum R, et al. Clearance of cervical human papillomavirus infection by topical application of curcumin and curcumin containing polyherbal cream: a phase II randomized controlled study. Asian Pac J Cancer Prev. 2013;14(10):5753-5759.

\section{Publish your work in this journal}

The Open Access Journal of Clinical Trials is an international, peerreviewed, open access journal publishing original research, reports, editorials, reviews and commentaries on all aspects of clinical trial design, management, legal, ethical and regulatory issues, case record form design, data collection, quality assurance and data auditing methodologies. The manuscript management system is completely online and includes a very quick and fair peer-review system, which is all easy to use. Visit http://www.dovepress.com/testimonials.php to read real quotes from published authors. 